\title{
Spiritual Practice \& Experience: A Kind of Contemporary Art View Leading to Civilization
}

\author{
Yuan Cheng ${ }^{1} \&$ Luodanni Liu ${ }^{1}$ \\ ${ }^{1}$ School of Art, Jimei University, Xiamen, China \\ Correspondence: Yuan Cheng, School of Art, Jimei University, Xiamen, Fujian Province, China. Tel: 86-158- \\ 0590-6990.
}

Received: April 2, 2021; Accepted: April 28, 2021; Published: May 1, 2021

Project: One of the results of the "Research on the creative thinking and evaluation mechanism of postgraduate experimental art teaching”(YJG1915), Jimei University.

\begin{abstract}
As a kind of perceptual sign of human spiritual dynamics and civilization height, "contemporary art" does not pursue the performing "sense of existence" under the spotlight, but leads to civilization and seeks its own "sense of belonging" through the current spiritual practice and exploration of the living noumenon of art - human - to the daily life world. Criticizing and deconstructing the traditional purist view of art, rejecting art for art's sake, and promoting "art noumenon" to "existence noumenon" - value significance of Karl Popper's so-called "Three Worlds", which are mutually dependent and promoting, mutually opposite and complementary, has been historically awakened and highlighted. Among them, "world two (experiencing world)", which is characterized by human spiritual practice and behavior experience, has the most life significance and artistic value "from culture to civilization". Define contemporary art from five key points combined with world two: reflecting the daily state of consciousness or mental state of human and society; highlighting the behavior, interaction, recognition of spiritual activities, and the everydayness of the effect on three worlds; an existing way of perceptually mastering the world; a symbol of apperception, personification, and living humanity world; and an artistic and dynamic world of connecting and driving the three worlds. Its fundamental logic is that: experience is cognition, that is, the continuous unity and dynamic unity of expression; it is the highest belonging and value conversion of culture leading to civilization; it is the true art that pursues truth, discovers possibility and highlights human nature.
\end{abstract}

Keywords: contemporary art, world II, cognitive experience, spiritual practice, from culture to civilization

\section{Introduction}

Art is artificial. Artificial things serve people, and the changes of people bring about artistic changes. This characteristic is artistic justice and authenticity. However, different from that traditional art regards works as conclusions which makes people look up to, contemporary artists put a higher value on the process that has dialogue, co-creation, and sharing of art definition with others, making process as works, works as art, art as artists, and artists as the living noumenon of art that break and innovate simultaneously. From "art before art" to the 1970s, contemporary artists completed a circle of natural closure and self-consistency, which returns to original nature, for the first time. In other words, the so-called "art", through cultural diversion and formalization, has gone from a series of "running away" for God, for the king, for capital, for art 's sake, and so on, and finally returned to human beings themselves - human life experience and cognition, as well as the language medium value and mind through which meaning evaluation can be obtained. In this sense, the so-called art is the observation of truth, which is actually the observation of problem consciousness and truth insight, the observation of why the human is human, the independent personality, thought and dignity, the observation of cognitive understanding and imagination of human nature and values of how to be a person and how to live as a person. In this sense, contemporary art and those traditional art supported by Imitation Theory and Formalism Theory draw a line. 


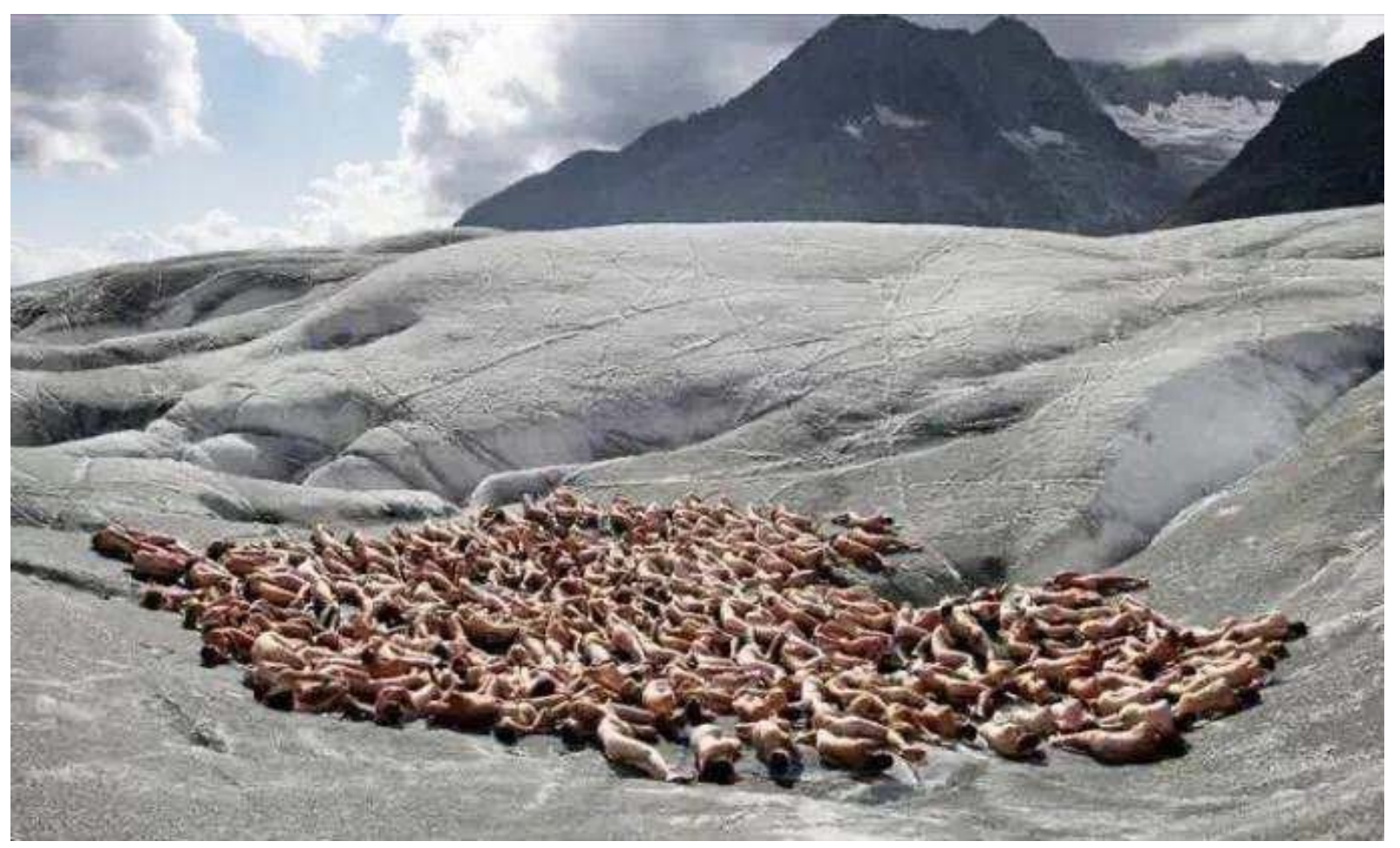

Figure 1. Spencer Tunick, Action Against Global Warming, 600 volunteers, 1800/2500m altitude, 2007

\section{Aletsch Glacier}

This is why those important experts and scholars lament that "there are no art only artists" in the world[1].

In fact, "art" is constantly defined and recognized by people of different times based on their own understanding and needs. Obviously, the definition, from content, form to the concept, is not art so much as the "picture frame" and "frame" for understanding and explaining art. Of course, it also includes "art circle", "art system" and so on. In fact, the reason is not complicated. Looking back at history, in classical antiquity only gods can make statues; in the middle ages, secular life was not regarded as a painting object; the classicist school not only did not think that workers, peasants, and other people at the bottom could enter the art but also regarded the modernist school as an anti-art beast; today, to the root, without profound insightful patterns, it can be described as paint daub that is inferior to photo - from ancient to modern times, it cannot but be said that no matter the content, theme or appearance form, "art" keeps transmutation, "differance" and continues to flow.

However, it is obvious that whether art has "self-discipline", "heteronomy" or "general discipline", whether it is "the manifestation of ideas" or "the purpose of existence" does not seem to matter. The important thing is "perceptual manifestation of human's essential power" that as the emotions are stirred in my heart, and I use poetic language to express it. I can't express it in words, so I continue to use the sound of sighing, open my throat singing, and dance. As a natural way for human beings to "master the world", as an avant-garde art of problem consciousness, seeking knowledge and truth, exploring the future and seeking the possibility, and as an experimental art of spiritual enlightenment and personality development, this kind of vanguard art dissolves the tradition of sharing, turns thought and attitude into form (content), and provides more choices and nutrition for the art table, this kind of surreal spiritual art, which is detached from fashion consumption and market utility, is going to "contemporary", that is, going out of the cultural ossification and stereotype that human sets and to the nature of live life. Borrowing the term of classical philosophy, it is moving towards the creative freely and developing world of the current practical spirit and spiritual practice of human that as "the sum of all kinds of social relations". 


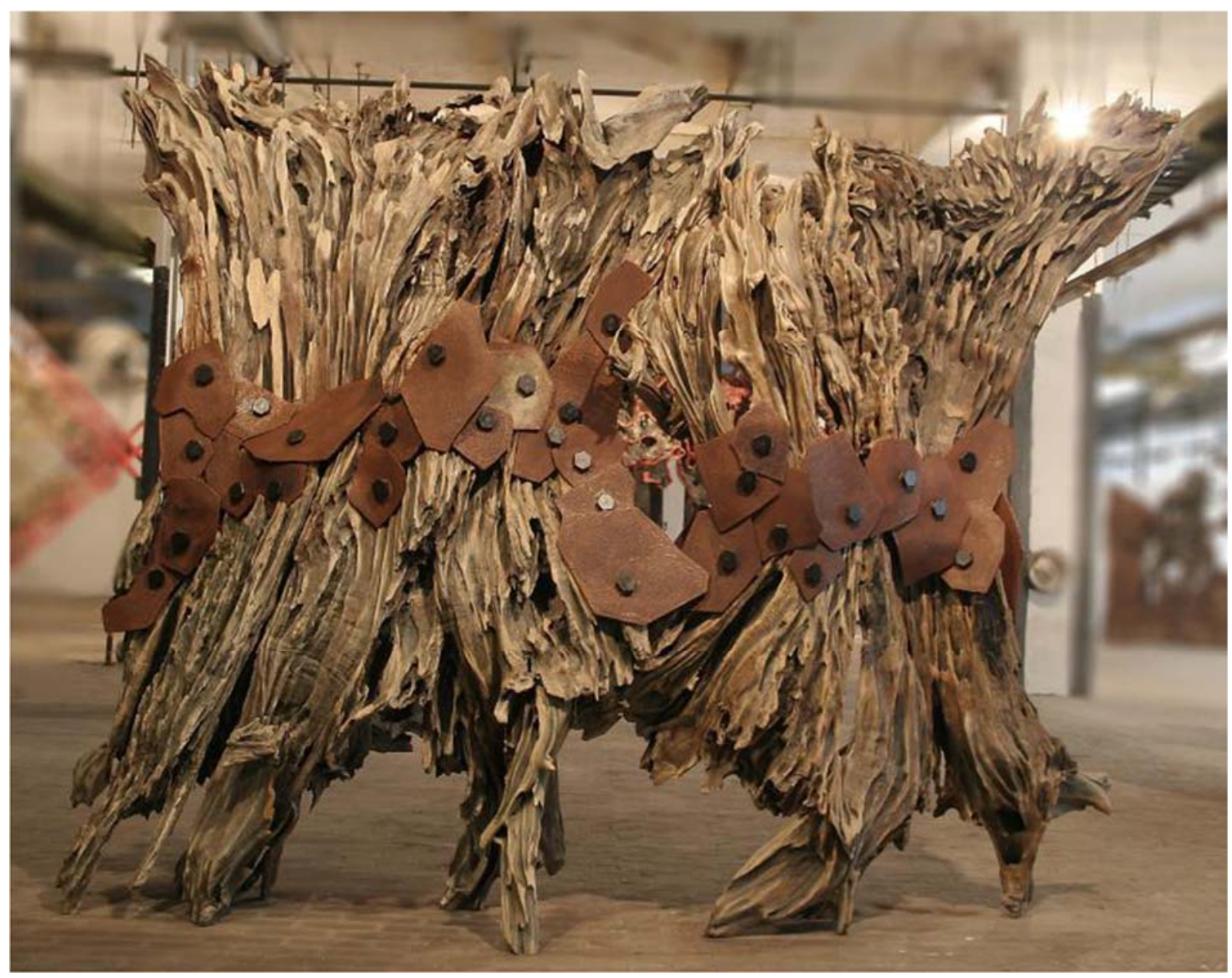

Figure 2. Xinmin Fu, Dialogue No.6, installation, 300×350×100cm, 2004

\section{Ontology of Contemporary Art}

In fact, the historical logic that the process from the perspective of body art and performance art is work, work is art, art is artist and artist is art noumenon, reflects the art understanding and standing in different time dimensions of pre-modern, modern and post-modern. As some live but die, and some die but live. In reality, there are still people living in the past, living in the present, and living in the future. People inevitably have different views on things. In recent years, in the debate on "contemporary art", some anti "contemporary" people instruct people to read the books of Popper, Toynbee, and others. However, according to the author, the essence of the recommended theory is exactly opposite to the intention of those who oppose "contemporary". Not to mention Toynbee's view of historiography, which regards the interaction of human civilization as the vision and opposes meeting the specific needs of somewhere in some time, whether he regards imitating ancestors and advocating creation as the distinction between "primitive society" and "civilized society", let alone whether his "anti-European Centrism" has the possibility of setting up another center. In terms of understanding the legitimacy of contemporary art, Popper, the most important critical rationalist falsifier in the 20th century, his theory has indeed provided a logical way and key to understanding how contemporary art develops universally for a long time, except for his ideological spirit of the isomorphism of works such as The Poverty of Historicism, The Open Society and Its Enemies, Unended Quest, and Emancipation Through Knowledge. What is more important is his book Objective Knowledge: An Evolutionary Approach, which was translated by the China Academy of Art in the 1980s. In other words, this theory, which reflects his "Three Worlds" thought and is closely related to contemporary art, especially with behavior and installation, is the theory of cognitive experience theory of contemporary art from the perspective of art.

Here is just a small discussion on the level of art noumenon. The academic circles know that Popper's theoretical expression of his three worlds has many places, but it mainly focuses on the above-mentioned Objective Knowledge and his co-author The Self and Its Brain with Eccles. According to Popper's order, the so-called three 
worlds are "first, the world of a physical object or material state; second, the world of consciousness or mental state, or the world of behavior intention about activities; third, the world of the objective content of thought, especially the world of scientific thought, poetic thought, and artistic works" [2]. Generally speaking, world one is the physical world, world two is the spiritual world, and world three is the objective knowledge world of textuality. To further understand its connotation, we can also use The Self and Its Brain to define the "all" content and relationship of the three worlds. In this way, the so-called content refers to the world one as a material existence, including the inorganic world, the biological world, the material matrix of artificial products, etc.; the world two as spiritual psychology, including subjective cognition, perceptual experience, thinking experience, emotional experience, quality intention experience, memory experience, dream experience, creative imagination experience, etc; the world three of artificial objectification includes "cultural tradition coding as material matrix" and "arguments for criticism of scientific problems", such as concepts, laws, images, etc.[3] The so-called relationship means that the three worlds is a dynamic whole that is mutually dependent and promoting, mutually opposite and complementary.

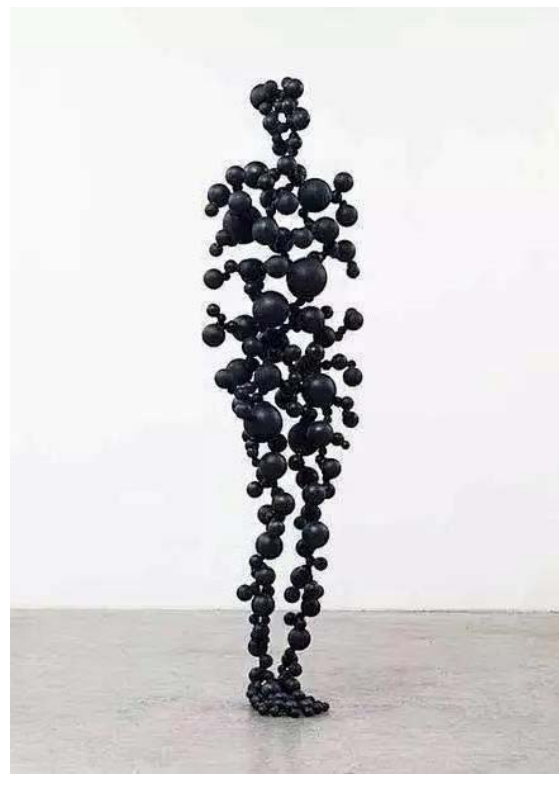

Figure 3. Antony Gormley Aperture: standing material (1) sculpture, 2003

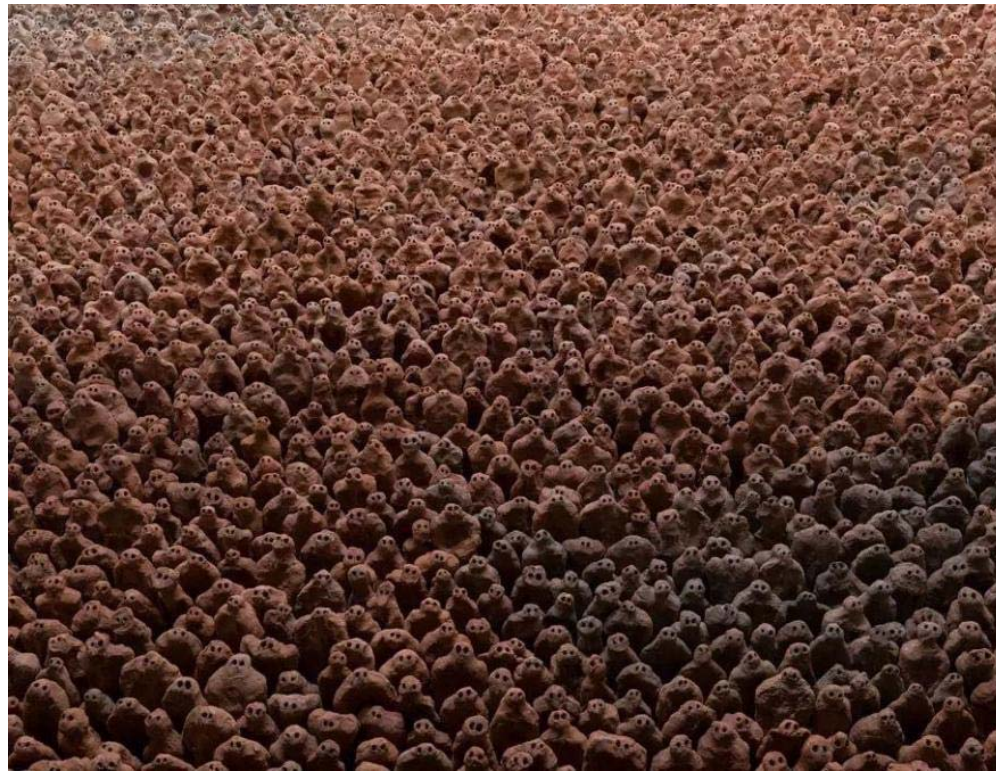

Figure 4. Antony Gormley Asian Land sculpture, 2003

It should be noted that in the past, influenced by the acceptance of fine arts and information decoding theory, people mostly focused on the autonomy of world three. What we should emphasize here is the unique and irreplaceable conversion from culture to the civilization of world two at the ecological level of post-industrial knowledge economy. Author thinks there are at least the following five points:

1) The so-called world two, in the new era of increasingly paying attention to physical and mental participation, interaction and contemporary experience, is itself a life with "behavioral intention", anwesen creating and realizing the meaning of life activities. This world, like the true knowledge of "love" and "childbirth", only exists in experiencing love and undergoing childbirth. In the "quantum" view, it is not only the dual reality of truth and philosophy but also has irreplaceable "unique" significance to life itself. Otherwise, theory can replace practice and literature can cover music. It can be said that in reality, world two, which is as old as the human itself, is a world that is often obscured and forgotten by the alienated world three. Its return and emergence can be described as a remote new world that reflects the daily "state of consciousness or mental state" of people and society, which is not only corresponding to the artistic motives such as accidental behavior and body installation, but also the direct recognition, biopsy, and expression of the original meaning of art.

2) As a spiritual behavior world or a practical spiritual world, world two not only regards the three worlds as people's thinking objects and means of production but also highlights the initiative of people's physical and mental activities, the experiential and constructive humanistic characteristics of cognitive behavior. In particular, As far as Popper's English interpretation of world two and his detailed list of eight aspects of "experience" such as 
perception, thinking, emotion, and creative imagination are concerned, English experience is synonymous with “体验（ti yan）” and “经历(jing li)、阅历(yue li)” in terms of nouns, while in terms of verbs and properties, it is the pronoun of "personal participation, personal experience" and even "feeling, discovery" words. Just like the direct participation of "reading", "looking" and "listening" in poetry and music appreciation. World two, as the representation of spiritual will, always highlights the behavior of spiritual activities, the recognition of the interaction between subject and object, and the daily role of the three worlds function.

3) In the way of existence, world two is more interlinked with Marx's "practice - spirit" theory of mastering the way of the world. The so-called practice - spirit is one of the main ways of mastering the world that Marx has discussed early [4]. In the academic circles, although there are different understandings and classifications of this theoretical connotation, the basic consensus is that the way of practice - spirit is not simply "practical" action, nor is it equal to "theoretical" speculation, but a special and artistic way of mastering the theory and practice. German "master" refers to the acquisition or possession of thinking, which means "sublating the opposition with the object" and "turning this content into mine" in spirit. Dialectically speaking, it is to emphasize the experiential nature of the cognitive practice, so as to make practice - spirit, that is, "spirit - practice", on the initiative of practice. Historically, this kind of spiritual practice driven by thought discovery and thought creation has generally become a kind of existence of "the first innovation force" - the contemporary art uplifting spiritual exploration and thought experiment is just its typical example.

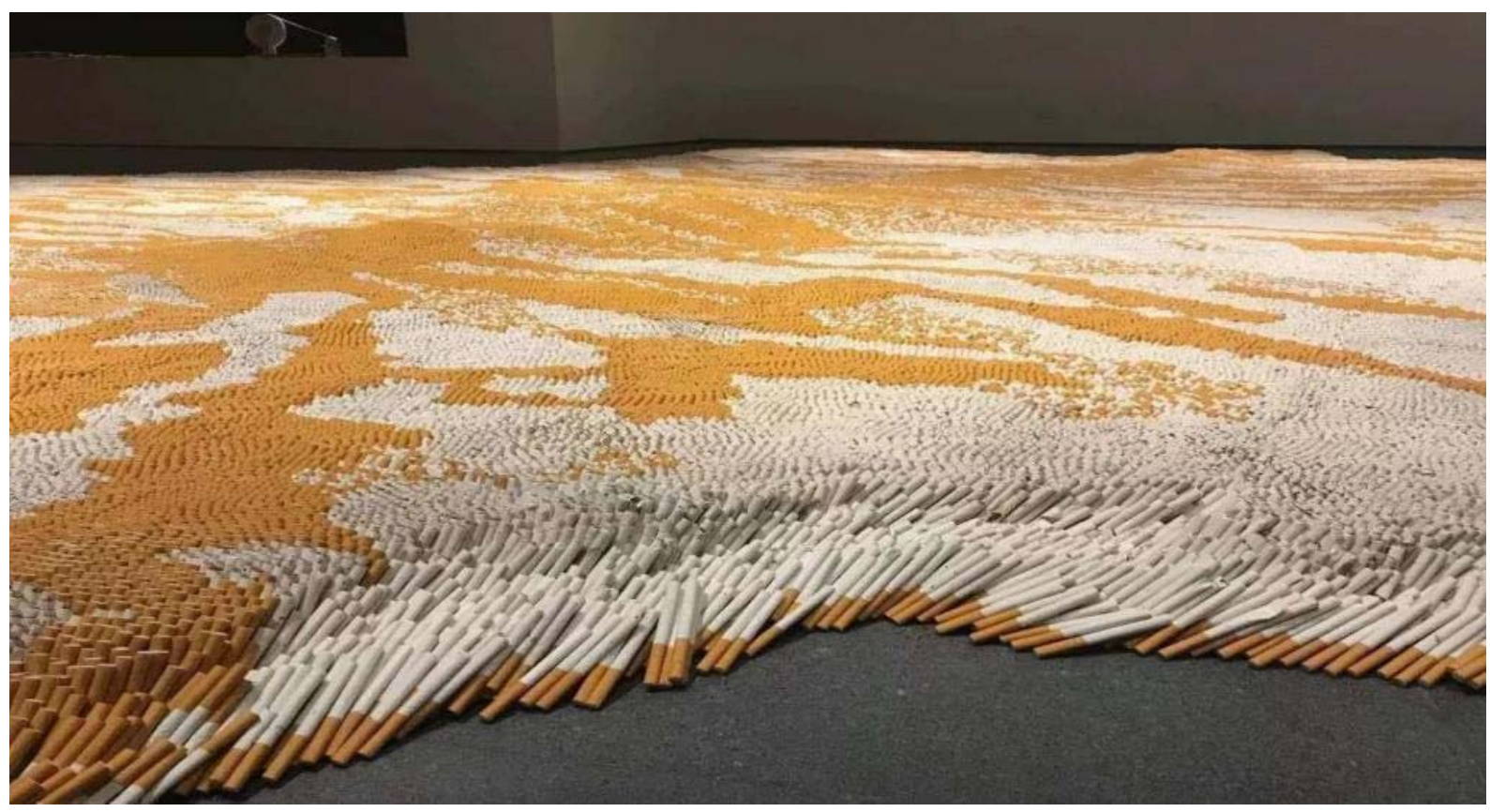

Figure 5. Bing Xu, Tiger Skin Carpet, installation, 2019

4) World two, in essence, is an advanced intuitive thinking sublimated into apperception and free will of the living world, is a "feeling through their own practice directly into the theorist" [5] on the level of personality of the human world. In terms of the above eight kinds of experience, whether perception, emotion, quality intention, or memory, dream, creative imagination and premonition, on the one hand, we can immediately see many Chinese and foreign works and pictures in our minds, such as Spring, The Seven Thousand Trees Plan, Equivalent, Lessons from the Dark And Heartbeat, or Asian Land, Aperture and Quantum Cloud, as well as the performance of The Artist Is Present by a woman who was described as a psychopath; of course, there are Spencer's Action Against Global Warming and Sleeping Beauty, Weiwei Ai's 100 Million Sunflower Seeds, Bing Xu's Book of Heaven and Tiger Skin Carpet, Xiaogang Zhang's Amnesia and Memory, Minjun Yue's Smiley Man, Yuguang, Lin's Going Home that describes societies' bottom, and Xinmin Fu's Dialogue, and Guoqiang Cai's Sky Ladder, etc. On the other hand, it can not be denied that these thinkers and experts of representation who take vision as the way of thinking, either through "social sculpture" or using image symbols "history laboratory", not only provide reality for the world but also bring a lot of enlightenment and suspense for life and society. 


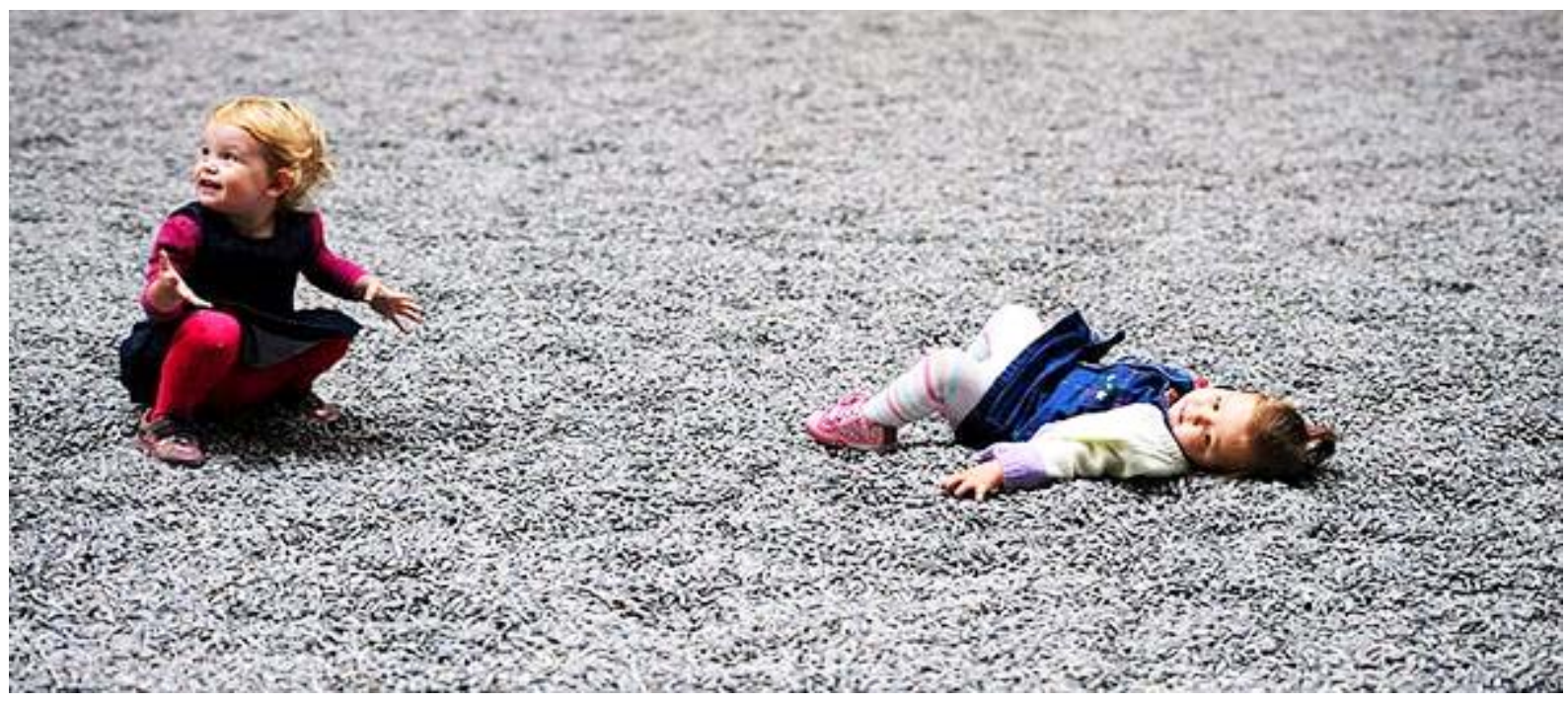

Figure 6. Weiwei Ai, 100 Million Sunflower Seeds, installation, 2010

5) World two is also a dynamic world that connects and drives the whole world. This world of why the human is human, which is constantly searching for the true meaning of life and pursuing the ideal existence, not only connects the material world with the artificial world of "human psychology, which is perceptually placed in front of us", but also enables people to discover the pragmatic potential of language materials dormant in world one or three by means of "brain farce", On the one hand, it borrows the characteristics of language medium signified signifier to inspire reality and shape society through some kind of "evocative structure". Just as language medium is discovered, so it is the identity of thought, content, and form. This is by no means pure personal empathy. In terms of the interpretability of word formation, artists should not only make themselves other but also change others and other things into themselves. Taking "glass" as an example, in addition to its daily function signified, it also has such signifiers as transparency and simplicity. Of course, in terms of verbal images, it can also be a nickname for fragile and even can extend the semantic meaning of the mutual paradoxes, such as distinction, closure, pseudo enlightenment, sharpness and danger. Obviously, the same medium has both the tension between feeling and idea and the multi-faceted relationship of tension, and the variability of semantic relationship brought by different contexts and audiences. At the same time, the symbolization and Intersubjectivity of image language also constitute the "non-identity" form and "riddle characteristics" of contemporary art. It can be said that it is the discovery of this specific, alienation, difficult to discipline and solidify universal sense and experience dormant in the media material and human prejudice that makes it a communicative semantic community with others.

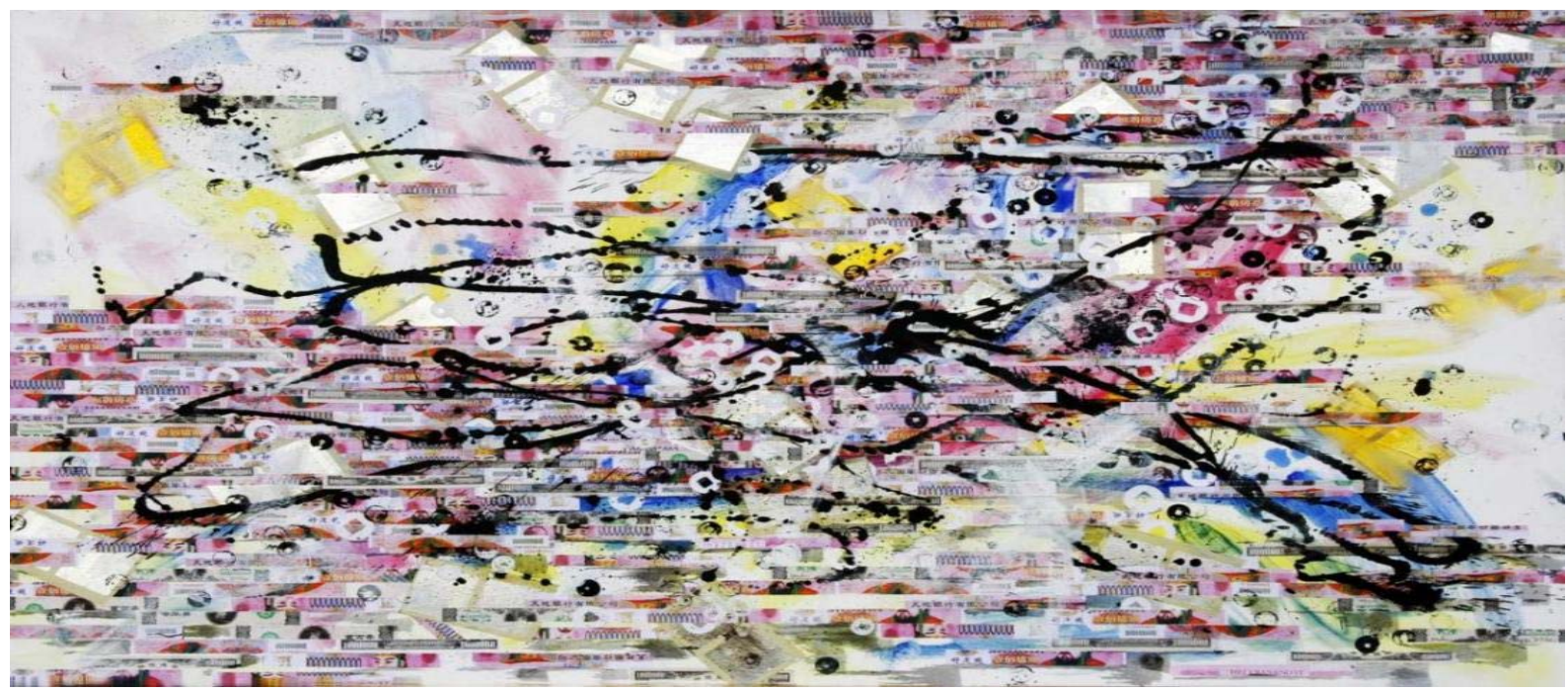

Figure 7. Yefu, Otherwhere, mixed-media painting, $188 \times 110 \mathrm{~cm}, 2014$ 


\section{Contemporary Art as Cultural Liberation and Civilization Conversion}

Exactly speaking, whether it is a part of the natural presentation or the presentation of art itself in this sense, just like science and technology, contemporary art adheres to this kind of active mechanism and logic, which makes the energy transformation and ascension of human civilization present a vivid, multidimensional and open style. When some art fans relegate contemporary art, including installation, behavior, body, etc., to rubbish, they obviously fail to realize that the world of spiritual practice is not only the world of experience but also the world of living people. The fundamental logic of this world is that experience is cognition, that is, the continuous unity and dynamic unity of expression. It is the highest belonging of culture towards civilization and the ultimate conversion of value significance.

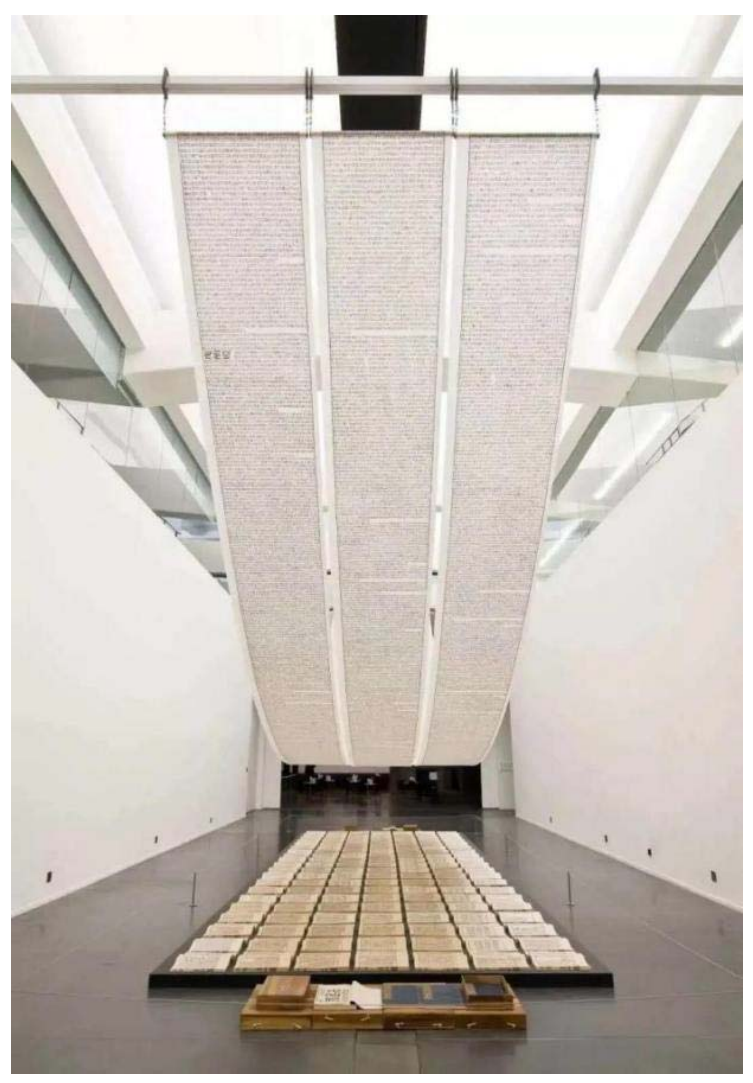

Figure 8. Bing Xu, Book of Heaven, installation, 1991

In this regard, people will certainly ask, is art practical, edification, form, cognition, entertainment, or aesthetics, philosophy? The answer here is: it seems that all of them are, but they are not typical, and the more typical substitutes seem to be less precious and scarce than art. Among these realistic and possible functions of art, "aesthetic" seems to be the most reliable, but in today's greasy "abuse of beauty", it is the most innumerable and disordered, vulgar and ineffective, and in this aspect, it seems to be inferior to decorative arts and crafts. No way, art itself is the most helpless problem, because it is a different problem to people themselves. The author thinks that there are two extremes in understanding art for a long time, namely, the controversy between formalism and existentialism represented by language ontology and life ontology. In theory, it is the difference between selftheory and heteronomy. In reality, it is the difference between tradition and contemporary. Among them, eclecticism is flooding constantly. Therefore, in terms of the personalization and ultimate meaning, it is the same way to solve the problem to attribute knowledge to cognition which is motive and purpose, and to attribute the spiritual feeling and cognition of art to motive and purpose. In this complex relationship full of misunderstanding, we firstly need the individual's spiritual self-enlightenment. Cover-removal = self-rescue. It's like the the value neutrality of light, in the individual itself, the effectiveness of light is as much as its enlightenment or altruism. This makes it more altruistic than egoistic in social effect. Just like the essential feature of sunshine, it belongs to the great use of inaction and useless talent. In other words, art is not art as long as it focuses on any of the above functions. 


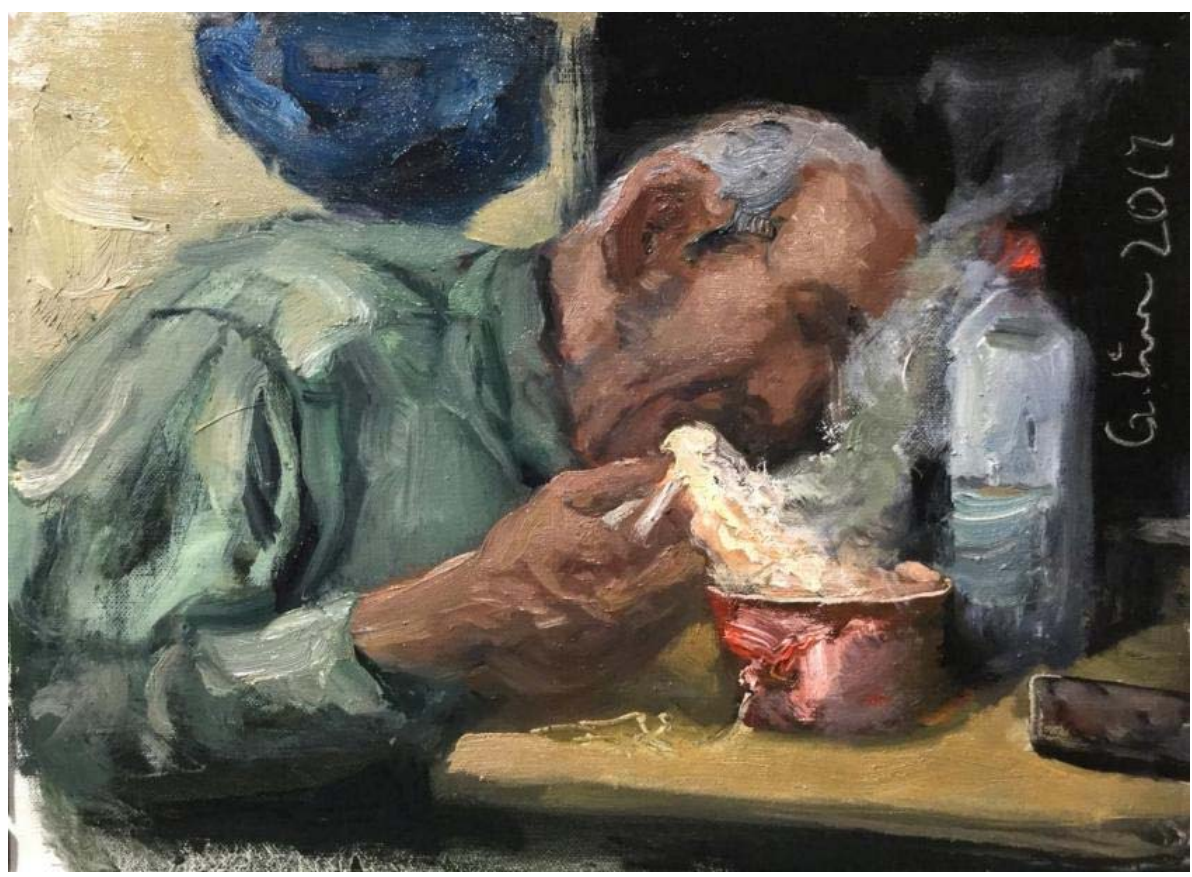

Figure 9. Yuguang Lin, Going Home, oil paint, 26×35cm, 2017

To be sure, people create the culture to serve people, instead of the contrary, otherwise, it is alienation. Human beings have experienced many kinds of alienation, such as religion, labor, politics, and so on. Of course, they will also face the alienation of science and technology, culture, and so on. It will be inconceivable if the cultural expression does not liberate people and if cultural development continues to add burdens and shackles to people. In fact, like "art for art's sake", "culture for culture's sake" is also a kind of alienation. In reality, the formalization and stereotype of culture mainly expresses and reflects the "sense of existence" rather than the "sense of belonging" peculiar to civilization. In this way, all activities of criticizing and dispelling historical and cultural paradoxes are the construction of civilization. And all art with this quality is the "contemporary art" towards civilization. To achieve this, it is not to create under the spotlight but to experience and discover in the crevices of life, in those "seemingly hopeless places" [6], and even to create the true art of embodying truth and revealing human nature with profound meaning on the tip of a needle. Thus, through art, let people become people, let culture towards civilization, "make art from civilized beauty salon into civilization itself." [7]

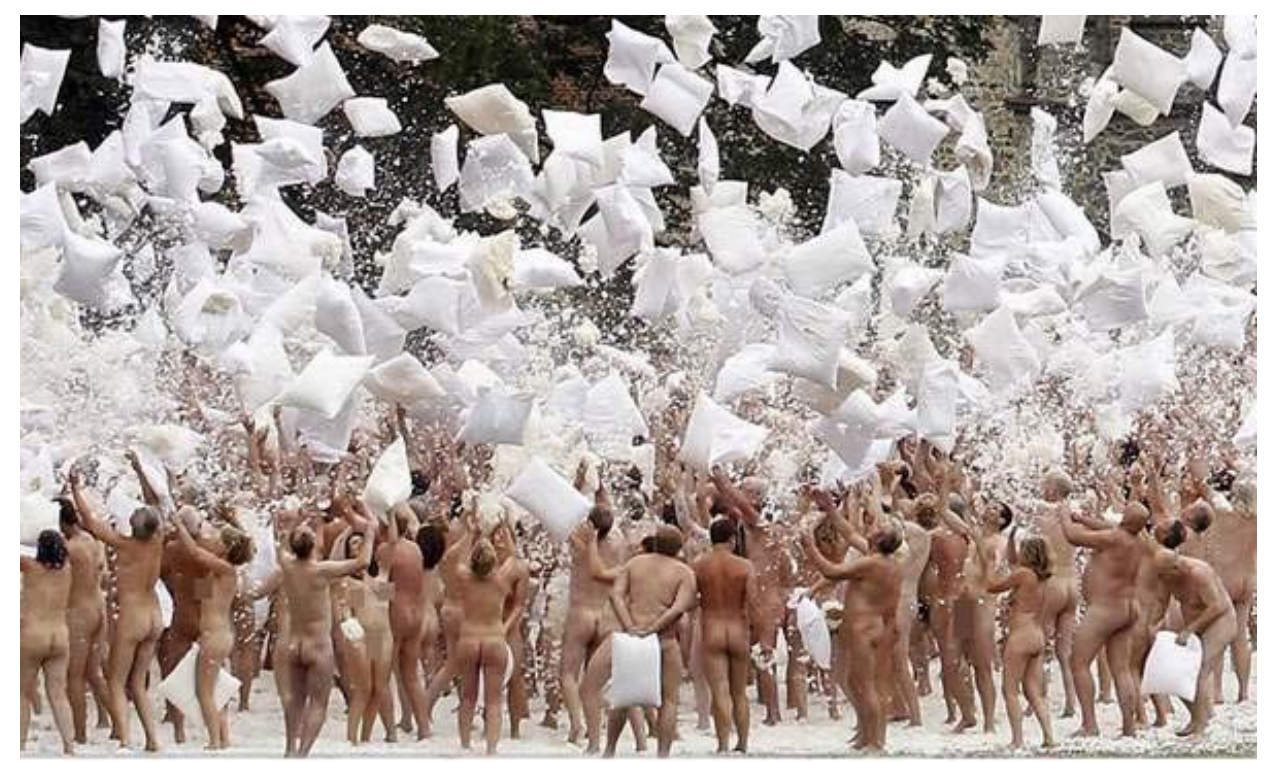

Figure 10. Spencer Tunick, Sleeping Beauty, performance video, 2011 


\section{Conclusion}

In contemporary art, there are no more than two aspects in the controversy of various artistic views. One pays attention to "fun" first, and the other emphasizes “good-looking" first. The former requires “interesting”(有意思), while the latter emphasizes "eye-pleasing feelings". Although both of them include each other(In Chinese words: 你中有我, 我中有你), the interesting and eye-pleasing feelings constitute their respective premises and elements. It's thought-provoking that in high welfare countries, art is mostly in fun, which makes people feel both “meaning(意)" and “thought(思)". Countries with higher welfare strive to discover the new, funny and interesting aspects of the world and everything. On the contrary, countries with lower welfare pay more attention to whether they are good-looking, eye-pleasing and decent. If the latter also requires "having meaning and thought", but it mostly "conveys" the meaning of a certain cultural and ideological community, rather than the meaning of the form of art itself, that is, the identity of content. Of course, it also rejects those creative orientations that reveal the truth of good-looking but meaningless.

In fact, in the pattern of globalization, the distinction of context and situation brings different art pursuit for "interesting" and "eye-pleasing". To put it simply, it is a controversy between art form and content in terms of function. In the high welfare countries, the identity of form and content of art is a proposition given by its historical situation; In the low welfare countries, form and content of art also has its given historical rules and dogmas as well. For example, while struggling to deal with the specific relationship between "art" and being an ideological "microphone", it should not only make art express a happy and good-looking appearance, but also interpret the art of high welfare state as empty and boring formalism. On the countrary, this is also the reason why Guoqiang Cai's pyrotechnic art has different meanings and effects in different countries and districts.

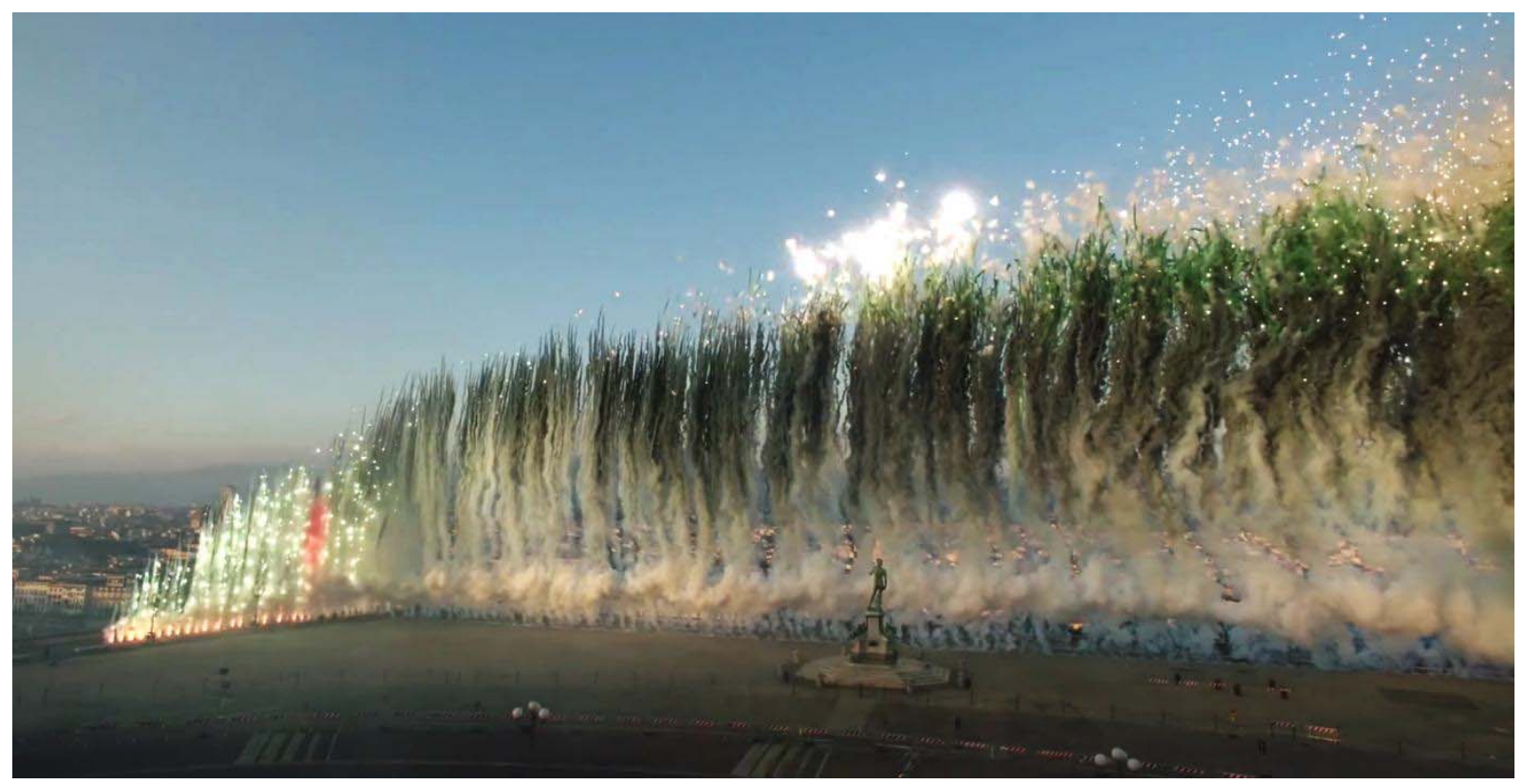

Figure 11. Guoqiang Cai, City of Flowers in the Sky, firework installation, 2018

Finally, it is necessary to emphasize that Karl Popper's living person "world of experience" (World 2) is not accidental at all, nor isolated. Whether Georges Bataille's L'expérience Intérieure(Inner Experience) and "view of sanctity" [8] or Maurice Merleau-Ponty's Phénoménologie de la Perception(Phenomenology of Perception), in fact, are to a great extent "the phenomenology of body"[9] based on the body and soul of human. Or this kind of "the phenomenology of mind" that as humanized and body-forth at the same time, just directly use living way of "art is experience" proceed on expression of openness in John Dewey's words[7]. Therefore, we can say art serves people, and is not mincing. Defining art is like laying a running track to define human. But, human is alive, running track is dead.The running track is a place that competes skills, fame and wealth, but art is not. The running track is not important, that is, the defined "art" is not important - running is important. Art only has running that pursues liberation rather than running track. If it has to express in perceptual way, it is, art is the light that moving constantly, whether it's candlelight, lightning, or the fight between light and darkness, and its spiritual practice and experience is fully colorful light of life, light of civilization. 


\section{References}

[1] [GBR] Gombrich. E. H., Jingzhong Fan (transl.). (2001). The Story of Art (Introduction). Tianjin: Tianjin People's Fine Arts Press.

[2] [GBR] K. Popper, Weiguang Shu, etc (transl.). (1987). Objectlve Knowledge: An Evolutionary Approach (p. 114). Shanghai: Shanghai Translation Press.

[3] [GBR] K. Popper, [AUS] J. G. Eccles. Shuli Ji (Ed.). (1987). Evolution of Scientific Knowledge (pp. 405-415). Beijing: Sanlian Bookstore.

[4] [GER] K. H. Marx, F. Engels, etc. Central Compilation \& Translation Bureau. (1972). Selected Works of Marx and Engels (Vol. 2, p. 104). Beijing: People's Press.

[5] [GER] K. H. Marx, Kun Liu (transl.). (1979). Economic and Philosophical Manuscripts 1844 (p. 78). Beijing: People's Press.

[6] [USA]Patricia O’B., Lynn Hunt (Ed.). (1989). The New Cultural History (p. 37). Berkeley, Calif.:University of California Press.

[7] [USA] J. Dewey, Ying Cheng (transl.). (2011). Art as Experience (Cover), Beijing: Jincheng Press.

[8] [FRA] G. Bataille, Guangji Wei (transl.). (2016). Inner Experience (pp. 30-31). Guilin: Guangxi Normal University Press.

[9] [FRA] M. Merleau-Ponty, Zhihui Jiang (transl.). (2001). Phenomenology of Perception (pp. 228-265, pp. 543571). Beijing:The Commercial Press.

\section{Copyrights}

Copyright for this article is retained by the author(s), with first publication rights granted to the journal.

This is an open-access article distributed under the terms and conditions of the Creative Commons Attribution license (http://creativecommons.org/licenses/by/4.0/). 